\title{
Associação de ractopamina e vitaminas antioxidantes para suínos em terminação
}

\author{
Association of ractopamine and antioxidants vitamins for finishing pigs
Roberta Abrami Monteiro Silva ${ }^{I}$ Graziela Drociunas Pacheco ${ }^{I *}$ Sylvia Luiza Vinokurovas Eduardo Raele de Oliveira ${ }^{I}$ David Fernandes Gavioli ${ }^{I}$ Arturo Pardo Lozano \\ Piero da Silva Agostini ${ }^{\text {II }}$ Ana Maria Bridi ${ }^{I I}$ Caio Abércio da Silva ${ }^{\text {II }}$
}

\section{RESUMO}

Objetivou-se neste estudo avaliar a inclusão de ractopamina e sua associação com as vitaminas antioxidantes $C$ e E em dietas de suínos em terminação durante 28 dias antes do abate sobre o desempenho, as características de carcaça e a qualidade da carne. Quarenta e oito suinos da linhagem Agroceres PIC (24 machos castrados e 24 fêmeas) foram distribuidos em delineamento experimental de blocos casualizados, em esquema fatorial 3x2, com três dietas: controle; controle + 10ppm de ractopamina; controle + complexo $(0,05 \%)$ de ractopamina com vitaminas antioxidantes $(10 \mathrm{ppm}$ de ractopamina $+200 \mathrm{mg}$ de vitamina $E+100 m g$ de vitamina $C \mathrm{~kg}^{-1}$ de ração) e dois gêneros (machos castrados e fêmeas). Foram avaliados o consumo de ração, o ganho de peso e a conversão alimentar dos animais. Os

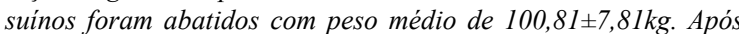
$o$ abate, as características de carcaça foram avaliadas e foram coletadas amostras do músculo Longissimus dorsi para a análise da qualidade da carne. Verificou-se diferença $(P<0,05)$ para a conversão alimentar, conformação da carcaça e pH final da carne dos animais que consumiram rações que continham ractopamina. A oxidação da carne foi menor para a dieta com o complexo (ractopamina + vitamina) em relação ao controle $\left(0,10 \mathrm{mg} \mathrm{kg^{-1 }} \mathrm{vs}\right.$ $0,13 \mathrm{mg} \mathrm{kg}^{-1}$ TBARS). O marmoreio da carne foi maior $(P<0,05)$ na dieta controle + ractopamina em relação à dieta controle. Os valores de vitamina $E$ no músculo foram mais elevados nos animais que ingeriram as vitaminas antioxidantes $\left(0,23 \mathrm{vs} 0,08 \mathrm{mg} \mathrm{kg}^{-1}\right.$ vit. E). Conclui-se que a inclusão de ractopamina, associada ou não às vitaminas antioxidantes, promoveu melhora na conversão alimentar e redução da oxidação lipídica da carne.

Palavras-chave: ácido ascórbico, agonista beta-adrenérgico, tecido adiposo, tocoferol.

\section{ABSTRACT}

The objective of the study was to evaluate the inclusion of ractopamine and its association with the antioxidant vitamins $C$ and $E$ in finishing pig diets during 28 days prior to slaughter on the performance, carcass traits and meat quality. Forty-eight Agroceres PIC line swine (24 barrows and 24 females) distributed in a randomized blocks factorial design in $3 \times 2$ (3 diets: control; control +10 ppm of ractopamine; control + complex $(0.05 \%)$ ractopamine with antioxidant vitamins (10ppm of ractopamine $+200 \mathrm{mg}$ of vitamin E+100mg of vitamin $\mathrm{C} \mathrm{kg}^{-1}$ of feed) and 2 sex (barrows and females). The feed intake, body weight gain and feed conversion were evaluated. When pigs reached $100.81 \pm 7.81 \mathrm{~kg}$ body weight, they were slaughtered and carcasses were evaluated. Samples of Longissimus dorsi muscle were taken to evaluate the meat quality. Diets with ractopamine improved $(P<0.05)$ feed conversion in pigs, carcass conformation and final $\mathrm{pH}$. The lipid oxidation decreased with the diet (ractopamine+vitamin) in relation to the control diet $\left(0.10 \mathrm{mg} \mathrm{kg}^{-1}\right.$ vs $0.13 \mathrm{mg} \mathrm{kg}^{-1}$ TBARS). The marbling was higher $(P<0.05)$ in the diet (control + ractopamine) in relation to the control diet. The levels of vitamin $E$ in the muscle were higher in pigs that were fed with antioxidant vitamins (0.23vs $0.08 \mathrm{mg} \mathrm{kg}^{-1}$ vit. E). It was concluded that the inclusion of ractopamine associated or not to antioxidant vitamins improved feed conversion ratio of animals and reduces the lipid oxidation in meat.

Key words: ascorbic acid, b-adrenergic agonist, adipose tissue, tocoferol.

\section{INTRODUÇ̃̃O}

A suinocultura atual produz animais precoces, eficientes e que apresentam carcaças com elevada relação carne:gordura, associada a um ótimo padrão de qualidade. O desafio principal é aumentar o rendimento de carne magra

IPrograma de Pós-graduação em Ciência Animal, Universidade de Estadual de Londrina (UEL), Londrina, PR, Brasil.

IIDepartamento de Zootecnia do Centro de Ciências Agrárias, UEL, 86057-970, Londrina, PR, Brasil. E-mail: grazivetuel@yahoo.com.br.

*Autor para correspondência.

IIIDepartamento de Ciência Animal e dos Alimentos, Universidade Autônoma de Barcelona (UAB), Barcelona, Espanha. Recebido 17.01.14 Aprovado 14.04.14 Devolvido pelo autor 23.09.14 CR-2014-0048.R1 
nas carcaças sem interferir negativamente na sua qualidade sensorial.

Com objetivo de se obter animais com essas características, são disponibilizados muitos recursos nutricionais, como, por exemplo, a ractopamina, que é um aditivo classificado como um repartidor de nutrientes e que promove melhorias no desempenho e nas características de carcaça. Podem ser utilizados também os antioxidantes, que são considerados aditivos que atuam reduzindo a oxidação da carne, melhorando, consequentemente, sua qualidade.

A ractopamina é um agonista betaadrenérgico que age no metabolismo animal, inibindo a lipogênese, estimulando a lipólise e retendo o nitrogênio, aumentando assim a síntese proteica. Com isso, há aumento na deposição do músculo pela hipertrofia do diâmetro das fibras musculares (BRIDI et al., 2006). Paralelo ao uso da ractopamina, com foco mais dirigido aos aspectos qualitativos e de segurança alimentar, a inclusão de aditivos antioxidantes nas rações constitui um recurso para diminuir as reações de oxidação na carne, uma vez que a presença de ácidos graxos polinsaturados na carne suína a expõe a maiores chances de oxidação.

Nas carnes, os antioxidantes mais utilizados são o ácido ascórbico (vitamina C) e o tocoferol (vitamina E). Segundo o NRC (1998), a necessidade de vitamina $\mathrm{E}$ no final do crescimento corporal para suínos é de $11 \mathrm{mg} \mathrm{kg}^{-1}$ de ração. Entretanto, quando a vitamina $\mathrm{E}$ é suplementada em níveis maiores (100 a 200 $\mathrm{mg} \mathrm{kg}^{-1}$ de ração), é verificado um efeito antioxidante, aumentando o tempo de vida útil da carne (SOUZA, 2001).

Dessa forma, o objetivo do presente trabalho foi avaliar os efeitos da utilização da ractopamina e de sua associação com vitaminas antioxidantes (vitamina $\mathrm{E}+$ vitamina $\mathrm{C}$ ) sobre o desempenho zootécnico, a qualidade de carcaça e da carne de suínos.

\section{MATERIAL E MÉTODOS}

Foram utilizados 48 suínos híbridos comerciais de genética Agroceres PIC, sendo 24 machos castrados e 24 fêmeas, de mesma idade (115 dias) e peso médio inicial de $71,5 \pm 5,85 \mathrm{~kg}$. Os animais, em número de dois por baia, foram alojados em instalações de alvenaria e piso compacto com $3 \mathrm{~m}^{2}$.

$\mathrm{O}$ delineamento experimental para as avaliações zootécnicas de carcaça e qualidade de carne foi em blocos ao acaso, de acordo com o peso inicial dos animais, num arranjo fatorial 3x2 (3 dietas e 2 gêneros). Para o teste de desempenho, a unidade experimental era a baia composta por dois animais de mesmo sexo, totalizando quatro repetições por tratamento. Para a análise da carcaça e qualidade de carne, cada animal foi considerado uma unidade experimental, totalizando oito repetições por tratamento.

Foram definidas três dietas experimentais: controle; controle $+10 \mathrm{ppm}$ de ractopamina e controle + complexo $(0,05 \%)$ de ractopamina com vitaminas antioxidantes $(0,2 \mathrm{~g}$ de ractopamina $+4 \mathrm{~g}$ de vitamina $\mathrm{E}+2 \mathrm{~g}$ de vitamina $\mathrm{C} \mathrm{kg}^{-1}$ de produto), ou, ainda, 10ppm de ractopamina $+200 \mathrm{mg}$ de vitamina $\mathrm{E}$ $+100 \mathrm{mg}$ de vitamina $\mathrm{C} \mathrm{kg}^{-1}$ de ração. As rações eram isonutrientes, sendo formuladas visando a atender as exigências previstas pela genética, atendendo no mínimo as recomendações nutricionais estabelecidas pelo NRC (1998). A composição percentual e os valores calculados das dietas experimentais encontram-se na tabela 1 .

Durante o período experimental (28 dias), os suínos receberam ração e água à vontade e foram pesados semanalmente. Posteriormente, foram calculados o consumo diário de ração, o ganho diário de peso e a conversão alimentar dos animais. O manejo pré-abate consistiu na retirada da ração 12 horas antes do embarque, permanecendo os animais em dieta hídrica até o abate. $\mathrm{O}$ abate foi realizado de acordo com a legislação vigente, seguindo as normas de Abate Humanitário (MAPA, 2000), sendo os suínos insensibilizados via corrente elétrica (350 volts e 1,3 ampères), com posterior sangria dos grandes vasos do pescoço.

Após o abate, escaldagem e evisceração, as carcaças foram divididas ao meio longitudinalmente e resfriadas à temperatura de $2 \pm 1^{\circ} \mathrm{C}$ por 24 horas. Após esse período, as carcaças foram avaliadas individualmente de acordo com as orientações da ABCS (1973). O pH da carne foi medido no músculo Longissimus dorsi, na altura da última costela, aos 45 minutos após o abate (pH inicial) e após 24 horas de resfriamento ( $\mathrm{pH}$ final). Foi retirada de cada meia carcaça esquerda uma amostra do músculo Longissimus dorsi para posteriores análises de qualidade de carne.

A cor foi medida pelo aparelho colorímetro portátil Minolta ${ }^{\circledR}$ CR10. Os componentes L*, a* e b* foram expressos no sistema de cor CIELAB. A análise de marmoreio seguiu padrões fotográficos $(1=$ traços de marmoreio e $5=$ marmoreio abundante). A capacidade de retenção de água da carne foi avaliada pela perda de água por gotejamento, segundo a técnica descrita por BOCCARD et al. (1981).

O método utilizado para a análise da oxidação lipídica foi o Indicativo de Substâncias 
Tabela 1 - Composição percentual, química e energética das dietas experimentais.

\begin{tabular}{lccc}
\hline Ingredientes & Controle & Controle + Ractopamina & Controle + Ractopamina + Vitaminas \\
\hline Milho & 72,84 & 72,84 & 72,84 \\
Farelo de soja & 22,60 & 22,60 & 22,60 \\
Óleo de Soja & 1,49 & 1,49 & 1,49 \\
Núcleo único suínos ${ }^{1}$ & 2,5 & 2,5 & 2,5 \\
L-Lisina-HCl & 0,47 & 0,47 & 0,47 \\
Inerte (caulim) & 0,1 & 0,05 & 0,05 \\
Ractopamina (2\%) & - & 0,05 & - \\
Complexo & - & - & 0,05 \\
Valores calculados & & & 16,710 \\
Proteína bruta (\%) & 16,710 & 4,309 & 16,710 \\
Extrato etéreo (\%) & 4,309 & 2,759 & 4,309 \\
Fibra bruta (\%) & 2,759 & 2,430 & 2,759 \\
Matéria mineral (\%) & 2,430 & 0,650 & 2,430 \\
Cálcio (\%) & 0,650 & 0,480 & 0,650 \\
Fósforo total (\%) & 0,480 & 3296,00 & 0,480 \\
Energia Met. (Kcal kg $\left.{ }^{-1}\right)$ & 3296,00 & 1,170 & 3296,00 \\
Lisina total (\%) & 1,170 & 1,170 \\
\hline
\end{tabular}

${ }^{1}$ Composição do núcleo único suínos por kg de produto: vit.A, 239.000UI; vit.B12, 538mcg; vit.D3, 66.000UI; vit.E, 517mg; vit.K 3,60mg; ácido fólico, 32mg; ácido pantotênico, 254mg; biotina, 1,1mg; niacina, 422mg; piridoxina, 41mg; riboflavina, 90mg; tiamina, 33mg; colina, 4g; promotor de crescimento, 2595mg; Ca, 231g; Co, 5,5mg; Cu, 5000mg; Fe, 2760mg; F, 881mg; P, 59g; I, 43mg; Mn, 1310mg; Se, $8,46 \mathrm{mg} ; \mathrm{Na}, 50 \mathrm{~g} ; \mathrm{Zn}, 3720 \mathrm{mg}$.

${ }^{2}$ Complexo $=\left(0,2 \mathrm{~g}\right.$ de ractopamina $+4 \mathrm{~g}$ de vitamina $\mathrm{E}+2 \mathrm{~g}$ de vitamina $\mathrm{C} \mathrm{kg}^{-1}$ de produto $)$.

Reativas ao Ácido Tiobarbitúrico (TBARS), segundo TARLADGIS et al. (1964), modificado por CRACKEL et al. (1988). As amostras destinadas à análise de maciez seguiram a metodologia descrita por BRIDI \& SILVA (2009). A força de cisalhamento foi tomada seguindo a metodologia de BOUTON et al. (1971). A vitamina $\mathrm{E}$ foi analisada por cromatografia líquida de alta eficiência (HPLC) (BRUBACHER et al., 1985).

Os dados obtidos foram submetidos à análise de variância e as médias comparadas pelo teste de Tukey $(\mathrm{P}<0,05)$, utilizando-se o programa SAEG (UFV, 1997).

\section{RESULTADOS E DISCUSSÃO}

$\mathrm{Na}$ tabela 2, observa-se que a inclusão de ractopamina associada ou não a vitaminas antioxidantes promoveu melhora na conversão alimentar dos animais $(\mathrm{P}<0,05)$. Este resultado pode estar relacionado ao direcionamento dos nutrientes para a deposição de tecido muscular, promovido pelo beta-adrenérgico, uma vez que suínos alimentados com ractopamina são mais eficientes na utilização dos nutrientes dietéticos (MARINHO et al., 2007).

ALMEIDA et al. (2010) verificaram que a suplementação de ractopamina (5ppm) melhorou em
$4 \%$ a conversão dos animais. No presente estudo, esta melhora foi de $8,5 \%$ nos animais que consumiram as dietas com $10 \mathrm{ppm}$ de ractopamina em relação à dieta controle.

ROSSI et al. (2010), utilizando dietas para suínos com associação de ractopamina e extratos cítricos, como antioxidantes, não observaram alteração no desempenho dos animais, o que pode confirmar que, no presente estudo, os efeitos relativos à melhora da conversão alimentar obtidos foram dependentes da inclusão da ractompamina nas dietas.

Em relação ao gênero, os machos apresentaram consumo diário de ração e conversão alimentar superiores aos das fêmeas, resultados estes que estão de acordo com MORAES et al. (2010), que observaram os mesmos resultados com inclusão de 10ppm de ractopamina em dietas de suínos. Assim, de acordo com os resultados obtidos, pode-se inferir que as fêmeas tiveram um melhor aproveitamento dos nutrientes da dieta.

Não houve interação entre as variáveis de desempenho analisadas. Para as características de carcaça (Tabela 3), foram verificadas diferenças $(\mathrm{P}<0,05)$ para a conformação, com favorecimento para o grupo tratado com $10 \mathrm{ppm}$ de ractopamina, porém, esse não diferiu estatisticamente do grupo tratado com a ractopamina associada às vitaminas 
Tabela 2 - Médias de consumo diário de ração (CDR), ganho diário de peso (GDP) e conversão alimentar (CA) de acordo com as dietas experimentais e os gêneros.

\begin{tabular}{|c|c|c|c|}
\hline \multirow[t]{2}{*}{ Dietas experimentais } & \multirow[b]{2}{*}{ CDR (kg) } & --Parâmetros & \multirow[b]{2}{*}{ CA } \\
\hline & & GDP (kg) & \\
\hline Controle & 2,81 & 1,01 & $2,79 \mathrm{~b}$ \\
\hline Controle + Ractopamina $^{1}$ & 2,69 & 1,04 & $2,57 \mathrm{a}$ \\
\hline Controle + Ractopamina + Vitaminas ${ }^{2}$ & 2,49 & 0,97 & $2,57 \mathrm{a}$ \\
\hline \multicolumn{4}{|l|}{ Gênero } \\
\hline Machos Castrados & $2,85 \mathrm{~b}$ & 1,03 & $2,76 \mathrm{~b}$ \\
\hline Fêmeas & $2,47 \mathrm{a}$ & 0,98 & $2,52 \mathrm{a}$ \\
\hline Coeficiente de variação (\%) & 10,54 & 8,75 & 6,56 \\
\hline
\end{tabular}

Médias seguidas de letras diferentes na mesma coluna indicam diferença no teste de Tukey $(\mathrm{P}<0,05)$.

${ }_{1}^{1}$ controle $+10 \mathrm{ppm}$ de ractopamina.

${ }^{2}$ controle + complexo (10ppm de ractopamina $+200 \mathrm{mg}$ de vitamina $\mathrm{E}+100 \mathrm{mg}$ de vitamina $\mathrm{C} / \mathrm{kg}$ de ração).

antioxidantes. Em relação ao gênero, as fêmeas apresentaram melhores resultados $(\mathrm{P}<0,05)$ de rendimento de carcaça $(77,18$ vs $76,23 \%)$, espessura de toucinho (10,16 vs $11,92 \mathrm{~mm})$, área de olho de lombo $\left(48,04\right.$ vs $\left.44,47 \mathrm{~cm}^{2}\right)$ e quantidade de carne magra na carcaça $(63,53$ vs $62,27 \mathrm{~kg})$, em comparação aos machos castrados. MORAES et al. (2010) também observaram diferença entre gêneros quanto ao rendimento de carcaça, sendo que as fêmeas apresentaram valores de $73,13 \%$ contra $70,38 \%$ dos machos castrados. Uma possível explicação para esse resultado pode estar relacionada ao fato de a ractopamina aumentar a carne magra da carcaça e, consequentemente, aumentar a deposição muscular, reduzindo a deposição de gordura. Essa observação foi mais evidente nas fêmeas.

Para as características ligadas à qualidade final da carne (Tabela 3), foi verificada diferença $(\mathrm{P}<0,05)$ para o $\mathrm{pH}$ final e marmoreio a favor do grupo tratado com $10 \mathrm{ppm}$ de ractopamina, porém não houve diferença em relação ao grupo tratado com a associação de ractopamina com vitaminas antioxidantes. De acordo com WOOD et al. (1994), o $\mathrm{pH}$ final da carne tende a ser mais elevado em suínos tratados com ractopamina. Isso ocorre porque os agonistas beta-adrenérgicos consomem o glicogênio muscular, resultando em menor produção e acúmulo de ácido láctico na carcaça pós-abate.

Os animais que consumiram dietas com associação de ractopamina e vitaminas antioxidantes apresentaram a carne com menores índices de oxidação, porém, os valores não diferiram do grupo que recebeu apenas 10 ppm de ractopamina $\left(0,10\right.$ vs $\left.0,12 \mathrm{mg} \mathrm{kg}^{-1}\right)$. Os menores valores observados no grupo que recebeu vitaminas antioxidantes $\left(0,10\right.$ vs $0,13 \mathrm{mg} \mathrm{kg}^{-1}$ da dieta controle) podem ser devido ao fato de os antioxidantes neutralizarem os radicais livres e interromper a cadeia de reações oxidativas, atuando como um escudo protetor ao redor de cada célula e reduzindo os danos de oxidação nos tecidos (PENNY, 2004).

Em relação aos valores de perda de líquido no descongelamento, perda de líquido na cocção e força de cisalhamento, não ocorreram diferenças $(\mathrm{P}>0,05)$ entre os tratamentos. Os resultados estão de acordo com os encontrados por BRIDI et al. (2006), que não encontraram diferenças $(\mathrm{P}>0,05)$ para perda de água no descongelamento e perda de água na cocção entre dietas controle e dietas com 10ppm de ractopamina.

A inclusão de $10 \mathrm{ppm}$ de ractopamina, utilizada no presente trabalho, não alterou a maciez da carne dos animais, dada pela força de cisalhamento. Entretanto, houve diferença $(\mathrm{P}<0,05)$ entre os gêneros. As fêmeas apresentaram carnes com menor resistência ao corte e, portanto, mais macias $(5,92$ vs $7,38 \mathrm{kgf}$ ). Estudos relatam que a maciez da carne pode estar associada ao diâmetro das fibras musculares, sendo que animais que apresentam maiores diâmetros, como aqueles que são suplementados com ractopamina, podem apresentar maior resistência ao corte e carne mais dura, fato que não foi observado neste trabalho.

Em relação aos níveis de vitamina $\mathrm{E}$ no músculo L. dorsi (Tabela 4), ocorreu diferença significativa $(\mathrm{P}<0,05)$ entre os tratamentos. Os animais que receberam a dieta contendo $10 \mathrm{ppm}$ de ractopamina associada a vitaminas antioxidantes apresentaram maiores valores de vitamina $\mathrm{E}$, comparados aos animais que receberam a dieta controle $(0,23$ vs $0,08 \mathrm{mg} \mathrm{kg}^{-1}$, respectivamente). A vitamina E protege os ácidos graxos mono e polinsaturados da carne (SOUZA \& SILVA, 2006) e, quando aplicada via ração em níveis entre 100 a $200 \mathrm{mg} \mathrm{kg}^{-1}$ de ração, produz efeito antioxidante, o que aumenta o tempo de vida útil da carne (SOUZA, 2001). 
Tabela 3 - Médias das características: peso de carcaça quente (PCQ), peso de carcaça resfriada (PCR), rendimento de carcaça (RC), conformação (CONF), espessura de toucinho (ET), profundidade do músculo (PM), área de olho de lombo (AOL), quantidade de carne magra na carcaça (QCMC), $\mathrm{pH}$ inicial e final, cor $\left(\mathrm{a}^{*}, \mathrm{~b}^{*} \mathrm{e} \mathrm{L}^{*}\right)$, perda de água por gotejamento (PAG), perda de líquido no descongelamento (PLD), perda de líquido na cocção (PLC), força de cisalhamento (FC), TBARs e marmoreio da carne de suínos submetidos a diferentes dietas experimentais.

\begin{tabular}{|c|c|c|c|c|c|c|}
\hline Parâmetros & Controle & $\begin{array}{l}\text { Controle }+ \\
\text { Ractopamina }^{1}\end{array}$ & $\begin{array}{l}\text { Controle }+ \\
\text { Ractopamina }+ \\
\text { Vitaminas }^{2}\end{array}$ & $\begin{array}{l}\text { Machos } \\
\text { castrados }\end{array}$ & Fêmeas & CV (\%) \\
\hline PCQ (kg) & 76,28 & 78,47 & 76,06 & 76,97 & 76,90 & 5,55 \\
\hline PCR (kg) & 74,43 & 76,61 & 74,28 & 74,99 & 75,22 & 5,58 \\
\hline RC (\%) & 76,05 & 77,15 & 76,91 & $76,23 \mathrm{~b}$ & 77,18 a & 1,87 \\
\hline CONF & $2,16 \mathrm{~b}$ & $2,52 \mathrm{a}$ & $2,34 \mathrm{ab}$ & $2,48 \mathrm{a}$ & $2,20 \mathrm{~b}$ & 17,70 \\
\hline $\mathrm{ET}(\mathrm{mm})$ & 11,28 & 11,07 & 10,77 & $11,92 \mathrm{~b}$ & $10,16 \mathrm{a}$ & 24,40 \\
\hline PM (mm) & 68,69 & 69,79 & 70,29 & 69,32 & 69,86 & 7,62 \\
\hline $\mathrm{AOL}\left(\mathrm{cm}^{2}\right)$ & 46,29 & 46,11 & 46,37 & $44,47 \mathrm{~b}$ & $48,04 \mathrm{a}$ & 8,38 \\
\hline QCMC & 62,67 & 62,85 & 63,17 & $62,27 \mathrm{~b}$ & $63,53 \mathrm{a}$ & 3,12 \\
\hline $\mathrm{pH}$ inicial & 5,88 & 5,84 & 5,71 & 5,81 & 5,81 & 4,97 \\
\hline $\mathrm{pH}$ final & $5,43 \mathrm{~b}$ & $5,54 \mathrm{a}$ & $5,48 \mathrm{ab}$ & 5,49 & 5,48 & 1,46 \\
\hline$a^{*}$ & 4,56 & 4,71 & 4,91 & 4,79 & 4,67 & 29,03 \\
\hline$b^{*}$ & 7,99 & 8,08 & 8,67 & 8,22 & 8,27 & 15,25 \\
\hline $\mathrm{L}^{*}$ & 56,17 & 54,00 & 58,66 & $53,66 \mathrm{a}$ & $58,90 \mathrm{~b}$ & 13,61 \\
\hline Marmoreio & $2,03 \mathrm{~b}$ & $2,75 \mathrm{a}$ & $2,28 \mathrm{ab}$ & 2,44 & 2,27 & 34,17 \\
\hline TBARs (mg kg ${ }^{-1}$ ) & $0,13 \mathrm{a}$ & $0,12 \mathrm{ab}$ & $0,10 \mathrm{~b}$ & 0,11 & 0,12 & 25,79 \\
\hline PAG (\%) & 4,74 & 3,34 & 4,27 & 3,67 & 4,56 & 40,49 \\
\hline PLD (\%) & 9,53 & 8,60 & 8,48 & 9,11 & 8,64 & 16,55 \\
\hline PLC (\%) & 38,30 & 37,44 & 37,47 & 37,24 & 38,17 & 5,03 \\
\hline FC (kgf) & 6,69 & 6,95 & 6,31 & $7,38 \mathrm{~b}$ & $5,92 \mathrm{a}$ & 17,25 \\
\hline
\end{tabular}

Médias seguidas de letras diferentes na mesma coluna indicam diferença no teste de Tukey $(\mathrm{P}<0,05) .{ }^{1}$ Ração controle +10 ppm de

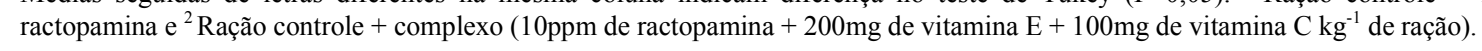

\section{CONCLUSÃO}

A inclusão de 10ppm de ractopamina, associada ou não às vitaminas antioxidantes $\mathrm{C}$ e E (respectivamente, 100 e $200 \mathrm{mg} \mathrm{kg}^{-1}$ de ração),

Tabela 4 - Valores de Vitamina E encontrados em amostras de carne de suínos submetidos a diferentes dietas experimentais.

\begin{tabular}{ll}
\hline Tratamentos & $\begin{array}{l}\text { Vitamina E } \\
\left(\mathrm{mg} \mathrm{kg}^{-1}\right)\end{array}$ \\
\hline Controle & $0,08(0,02) \mathrm{b}$ \\
Controle + Ractopamina + Vitaminas ${ }^{1}$ & $0,23(0,05) \mathrm{a}$ \\
Gênero & $0,15(0,08)$ \\
Machos castrados & $0,15(0,08)$ \\
Fêmeas & 31,57 \\
Coeficiente de variação $(\%)$ & \\
\hline
\end{tabular}

Médias seguidas de letras diferentes na mesma coluna indicam diferença no teste de Tukey $(\mathrm{P}<0,05)$.

${ }^{1}$ Controle + complexo $(10 \mathrm{ppm}$ de ractopamina $+200 \mathrm{mg}$ de vitamina $\mathrm{E}+100 \mathrm{mg}$ de vitamina $\mathrm{C} \mathrm{kg}^{-1}$ de ração). melhorou a conversão alimentar dos suínos e diminuiu a oxidação lipídica da carne suína.

\section{COMITÊ DE ÉTICA E BIOSSEGURANÇA}

Declaramos que os animais utilizados em experimentação que originou o artigo "Associação de ractopamina e vitaminas antioxidantes para suínos em terminação", encaminhado para publicação na revista Ciência Rural, foram avaliados sob os princípios do bem-estar animal.

\section{REFERÊNCIAS}

ALMEIDA, V.V. et al. Ractopamina, cromo-metionina e suas combinações como aditivos modificadores do metabolismo de suínos em crescimento e terminação. Revista Brasileira de Zootecnia, v.39, n.9, p.1969-1977, 2010. Disponível em: $<$ http://www.scielo.br/scielo.php?script=sci_arttext\&pid $=$ S1516-35982010000900015 $>$. Acesso em: 10 mar. 2014. doi: 10.1590/S1516-35982010000900015.

ASSOCIAÇÃO BRASILEIRA DE CRIADORES DE SUÍNOS (ABCS). Métodos brasileiro de classificação de carcaças. 2.ed. Estrela, 1973. 17p.

BOCCARD, R. et al. Procedures for measuring meat quality characteristics in beef production experiments. Report of a working 
group in the commission of the European communities (CEC) beef production research programme. Livestock Production Science, v.8, p.385-397, 1981

BOUTON, P.E. et al. Effect of ultimate $\mathrm{pH}$ upon the water-holding capacity and tenderness of mutton. Journal of Food Science, v.36, p.435-439, 1971. Disponível em: <http://onlinelibrary.wiley.com/ doi/10.1111/j.1365-2621.1971.tb06382.x/abstract>. Acesso em: 16 jan. 2014. doi: 10.1111/j.1365-2621.1971.tb06382.x.

BRASIL. Ministério da Agricultura, Pecuária e Abastecimento Instrução Normativa $n^{\circ} 3$, de 7 de janeiro de 2000. Regulamento técnico de métodos de insensibilização para o abate humanitário de animais de açougue. Diário Oficial da União, Brasília, 24 jan. 2000. p.14-16. Disponível em: <http://extranet.agricultura.gov.br/ sislegisconsulta/servlet $/$ VisualizarAnexo?id=12869>. Acesso em: 10 mar. 2014

BRIDI, A.M. et al. Efeito do genótipo halotano, da ractopamina e do sexo do animal na qualidade da carne suína. Revista da Sociedade Brasileira de Zootecnia, v.35, n.5, p.2027-2033, 2006. Disponível em: <http://www.scielo.br/scielo.php?script=sci artt ext\&pid $=$ S151635982006000700021 > . Acesso em: 16 jan. 2014 doi: 10.1590/S1516-35982006000700021.

BRIDI, A.M.; SILVA,C.A. Avaliação da carne suína. Londrina: Midiograf, 2009. 120p.

BRUBACHER, G. et al. Methods for the determination of vitamins in food. London: Elsevier Applied Science Publishers, 1985, p. 33-50.

CRACKEL, R.L. et al. Some further observations on the TBA test as an index of lipid oxidation in meats. Food Chemistry, v.28, n.3, p.187-196, 1988. Disponível em: <http://www.sciencedirect.com/ science/article/pii/0308814688900507>. Acesso em: 16 jan. 2014 doi: 10.1016/0308-8146(88)90050-7.

MARINHO, P.C. et al. Efeito da ractopamina e de métodos de formulação de dietas sobre o desempenho e as características de carcaça de suínos machos castrados em terminação. Revista Brasileira de Zootecnia, v.36, p.1061-1068, 2007. Disponível em: <http://www.scielo.br/pdf/rbz/v36n4s0/11.pdf $>$. Acesso em: 17 abr. 2014. doi: 10.1590/S1516- 35982007000500011.

MORAES, E. et al. Ractopamina em dietas para suínos machos imunocastrados, castrados e fêmeas. Ciência Rural, v.40, n.2, p.409-414, 2010. Disponível em: <http://www.scielo.br/scielo. php?script $=$ sci_arttext\&pid $=$ S0103-84782010000200024 $>$. Acessoem:10mar.2014.doi:10.1590/S0103-84782010000200024.

NRC. Nutrient requirements of swine. 10.ed. Washington: National Academy, 1998. 210p.

PENNY, P. Elevação dos teores de DHA ômega-3 e selênio na carne suína: agregando valor para consumidores e produtores. Porkworld, v.1, n.22, p.66-69, 2004.

ROSSI, C.A.R. et al. Alimentação de suínos em terminação com dietas contend ractopamina e estratos cítricos: desempenho e características de carcaça. Ciência Rural, v.40, n.11, p.2343-2349, 2010. Disponível em: <http://www.scielo.br/ scielo.php? pid $=\mathrm{S} 0103-84782010001100015 \&$ script $=$ sci arttext>. Acesso em: 10 mar. 2014. doi: 10.1590/S010384782010001100015

SAEG. Sistema para análises estatísticas. Versão 7.1.Viçosa: Fundação Arthur Bernardes, 1997. 150p.

SOUZA, V.L.F. A influência de dietas suplementadas com vitamina $E$ desde o crescimento e terminação do suíno até o presunto cozido no seu período de validade: índices zootécnicos, estabilidade oxidativa, perfil de ácidos graxos, colesterol e óxidos de colesterol. 2001. 222 fls. Tese (Doutorado em Ciência de Alimentos) - Universidade Estadual de Londrina, Londrina, PR.

SOUZA, V.L.F.; SILVA, R.S.S.F. Dietary vitamin Esupplementation on cholesterol and cholesterol oxides of pig meat and cooked ham. Brazilian Archives of Biology and Technology, v.49, p.197-205, 2006. Disponível em: $<$ http://www.scielo.br/scielo.php?script=sci arttext\&pid=S1516-89132006000300003 $>$. Acesso em: 10 mar. 2014. doi: 10.1590/S1516-89132006000300003.

TARLADGIS, B.G. et al. Chemistry of 2- thiobarbituric test for determination of oxidative rancidity in foods. II. Formation of the TBA- malonaldehyde complex without acid-heat treatment. Journal of the Science of Food and Agriculture, v.5, n.9, p.602604, 1964. Disponível em: <http://onlinelibrary.wiley.com/ doi/10.1002/jsfa.2740150904/abstract>. Acesso em: 16 jan. 2014. doi: $10.1002 /$ jsfa.2740150904.

WOOD, J.D. et al. Control and manipulation of meat quality. In: COLE, D.J.A. et al. (Eds.). Principles of pig science. London: Nottingham University, 1994. p.446-448. 